\title{
Diretrizes de capacitação para o uso de biogás de esgoto no Brasil
}

\section{Training guidelines for the use of biogas from sewage in Brazil}

Data de entrada: 12/03/2017

Data de aprovação: 03/05/2017

Hélinah Cardoso Moreira*/Gustavo Rafael Collere Possetti/Reinaldo Castro Souza/Roberta Hessmann Knopki/ Rodrigo Augusto Franco de Oliveira Zawadzki

DOI:10.4322/dae.2017.021

\section{Resumo}

Esta nota técnica reporta a estruturação de um processo de capacitação sobre aproveitamento energético de biogás de estações de tratamento de esgoto, especialmente adaptado às condições brasileiras. Esse processo foi realizado no âmbito do PROBIOGÁS, um projeto de cooperação internacional entre os governos do Brasil e da Alemanha. Para tanto, inicialmente definiu-se a estratégia de capacitação e quantificou-se a demanda sobre capacitação na área. Identificou-se que o setor possui uma necessidade de treinamento de, pelo menos, 691 profissionais distribuídos pelo país. Depois disso, realizou-se a capacitação de multiplicadores de conhecimento. Eles foram criteriosamente selecionados e desenvolveram uma grade curricular inédita e capaz de orientar o processo de capacitação no tema no Brasil. Os multiplicadores ainda conceberam projetos de transferência do conhecimento, sendo que os resultados obtidos com a implementação do projeto no Estado do Paraná são aqui apresentados. Esse projeto, conduzido por meio de uma parceria entre uma escola de ensino profissionalizante e um prestador de serviços de saneamento, capacitou 100 profissionais. 0 processo de capacitação em questão disponibilizou importantes diretrizes para a disseminação estruturada dos conhecimentos acerca do uso do biogás oriundo do tratamento do esgoto em nível nacional. Palavras-chave: Biogás. Estação de tratamento de esgoto. Capacitação. Grade curricular.

\section{Abstract}

This technical note reports the structuring of a training process on the biogas energy utilization of sewage treatment plants, specially adapted to Brazilian conditions. This process was carried out within PROBIOGÁS, an international cooperation project between Brazil and Germany governments. For that, the training strategy was initially defined and the demand for training in the area was quantified. It was identified that the sector has a need for training of at least 691 professionals distributed throughout the country. Afterward, the training of knowledge multipliers was carried out. They were carefully selected and developed an unprecedented cur-

\footnotetext{
Hélinah Cardoso Moreira - Engenheira Ambiental pela UFRJ. Mestranda em Engenharia Urbana e Ambiental na PUC-RJ. Coordena ações na área de esgotos do PROBIOGÁS.

Gustavo Rafael Collere Possetti - Engenheiro Ambiental pela UFPR e Engenheiro Eletricista pela UTFPR. Mestre e Doutor em Ciências pela UTFPR. Gerente da Assessoria de Pesquisa e Desenvolvimento da Sanepar. Professor do Programa de Mestrado Profissional em Governança e Sustentabilidade do ISAE.

Reinaldo Castro Souza - Engenheiro Eletricista UFJF, Mestre em Engenharia de Sistemas PUC-Rio, PhD em Estatística Warwick University, UK e Pós-doutor em Econometria, London School of Economics, UK. Professor Titular do DEE e Acadêmico da ANE (Academia Nacional de Engenharia).

Roberta Hessmann Knopki - Engenheira Ambiental pela UFPR. Pós-graduada em Gestão da Produção pela FAE Business School. Coordena ações na área de licenciamento ambiental e capacitação do PROBIOGÁS.

Rodrigo Augusto Franco de Oliveira Zawadzki - Tecnólogo em Química Ambiental pela UTFPR. Mestre em Química pela UFPR. Doutorando em Engenharia Civil e Saneamento na UTFPR. Professor pleno e consultor técnico do Instituto SENAI de Tecnologia em Meio Ambiente e Química. *Endereço para correspondência: RGesellchaft für Internationale Zusammenarbeit (GIZ) Gmb,SCN, Quadra 01, Bloco C, Sala 1.501,Ed. Brasília Trade Center, CEP 70.711-902. Brasília-DF. Telefone: (61) 3963-7524. E-mail: helinah.cardosoagiz.de
} 
riculum that could guide the training process in biogas area in Brazil. The multipliers also conceived knowledge transfer projects, and the results obtained with the implementation of the project in the Paraná State are showed. This project, conducted by mean of a partnership between a vocational school and a sanitation service provider, trained 100 professionals. The training process detailed here provided important guidelines for the structured dissemination of knowledge about the use of biogas from sewage treatment in Brazil. Keywords: Biogas. Wastewater treatment plant. Training. Curricular grade.

\section{INTRODUÇÃO}

Atualmente, o Brasil conta com um índice de cobertura de coleta e tratamento de esgoto sanitário de aproximadamente $42 \%$ (Ministério das Cidades, 2016). De acordo com as metas do Plano Nacional de Saneamento Básico (PLANSAB, 2013), esse índice deverá ser superior a $90 \%$ até o ano de 2033, o que indica que tais serviços devem aumentar significativamente nos próximos anos. Para que essa meta seja atingida, novas estações de tratamento de esgoto (ETEs) deverão ser construídas, e as existentes deverão ser ampliadas ou modernizadas.

O estado da arte sobre tratamento de esgotos no Brasil reflete a consolidação da tecnologia anaeróbia (VAN HAANDEL et al., 2006; CHERNICHARO et al., 2015), totalizando cerca de 908 reatores anaeróbios que atendem a cerca de 23 milhões de habitantes e que produzem rotineiramente o biogás (CHERNICHARO et al., 2017). 0 biogás também pode ser gerado em ETEs a partir da digestão anaeróbia do lodo. Dessa forma, é comum encontrar digestores de lodo que produzem biogás em ETEs dotadas de sistemas aeróbios de tratamento de esgoto, sobretudo em plantas de grande porte. Destaca-se que a utilização dos sistemas de lodos ativados é preponderante em ETEs brasileiras com capacidade instalada superior a 100 mil habitantes, representando $44 \%$ de todas as alternativas adotadas (CHERNICHARO et al., 2017). Logo, há um potencial significativo de produção de biogás em ETEs brasileiras.
O biogás é uma fonte de energia renovável que, mediante recuperação, pode proporcionar um aumento da eficiência operacional das ETEs (SILVEIRA et al., 2015). Além disso, o aproveitamento do biogás contribui para a redução das emissões de gases indutores do efeito estufa (IPCC, 2006; ICLEI, 2010), bem como para a mitigação das emissões de maus odores nas envoltórias das ETEs (NOYOLA et al., 2006; CHERNICHARO et al., 2010).

O uso energético do biogás está bem fundamentado na literatura (BALAT, 2009; PÖSCHL et al., 2010; YANWEN SHEN et al., 2015). Há trabalhos que demonstram que o biogás pode auxiliar na redução dos custos operacionais de ETEs associados com energia elétrica (Mc CARTY et al., 2011; LOBATO, 2011; LIMA, 2014; VALENTE, 2015; ROSENFELDT et al., 2015; CABRAL, 2016) e com a gestão de lodos e escumas (BOUGRIER et al., 2006; LOBATO, 2011; ROSA et al., 2016). Camargo (2009), inclusive, discute a utilização do biogás como combustível veicular. No entanto, o uso do biogás proveniente do tratamento de esgoto sanitário ainda é incipiente no Brasil, apesar das discussões sobre o assunto terem sido iniciadas na década de 70 (NETTO, 1977).

A concepção e a operação mais eficiente de ETEs a partir do aproveitamento do potencial energético do biogás devem ser consideradas nas fases de projeto, de construção e de operação desses sistemas. Contudo, para a integração desse processo nos sistemas de tratamento de esgoto, é fundamental a qualificação dos profissionais do setor. 
De modo geral, o setor de saneamento brasileiro apresenta uma grande demanda por capacitação, tendo como desafios a melhoria da capacidade de planejar suas ações e de estruturar o município em nível técnico administrativo (PORTAL SANEAMENTO BÁSICO, 2013). Em especial no setor de tratamento de esgoto sanitário, busca-se a melhoria contínua dos processos para atendimento dos novos marcos legais ambientais, bem como a sustentabilidade dos modelos de negócios. Nesse sentido, as iniciativas de capacitação podem gerar benefícios significativos. Zawadzki et al. (2016) reportaram um estudo de caso em que treinamentos voltados para o aprimoramento de rotinas operacionais proporcionaram uma economia de aproximadamente 200.000 reais por ano em uma ETE operando com sistema de aeração prolongada.

O primeiro curso do Brasil destinado à formação e aperfeiçoamento de Tratadores e Auxiliares de Tratamento de Esgotos foi organizado em 1945 (REPARTIÇÃO DE ÁGUAS E ESGOTOS DE SÃO PAULO, 1991). O setor já foi contemplado com iniciativas pontuais de capacitação no âmbito do Plano Nacional de Saneamento - Planasa (PIRES, 1993) e, em seguida, da Rede Nacional de Capacitação e Extensão Tecnológica em Saneamento Ambiental - ReCESA (ReCESA, 2008), ambos programas de governo. No entanto, faz-se necessário ainda o desenvolvimento de um plano nacional estratégico de capacitação voltado para o tratamento de esgotos, em especial vinculado ao biogás.

Entre os anos de 2013 e 2017, a Secretaria Nacional de Saneamento Ambiental (SNSA) do Ministério das Cidades coordenou, com o apoio da Deutsche Gesellschaft für Internationale Zusammenarbeit (GIZ) $\mathrm{GmbH}$, um projeto de fomento ao aproveitamento energético de biogás no Brasil, o PROBIOGÁS (MCIDADES, 2016). O PROBIOGÁS teve como foco principal o aproveitamento do biogás gerado no tratamento anaeróbio dos esgotos sanitários, dos resíduos sólidos urbanos, agropecuários e dos efluentes agroindustriais.

De forma mais detalhada, o projeto atuou junto a órgãos governamentais em prol da melhoria das condições regulatórias relacionadas à produção de energia a partir do biogás, aproximou as instituições de ensino e pesquisa e fomentou a indústria nacional de biogás. Uma das grandes ações do projeto foi a capacitação de profissionais brasileiros em diversos níveis, contemplando atores que integram toda a cadeia de biogás, tendo atingido cerca de 2 mil pessoas (PROBIOGÁS, 2017).

Ao longo do projeto, diagnosticou-se que existe uma demanda nacional por capacitação de profissionais na área de aproveitamento energético de biogás proveniente de ETEs. No catálogo nacional de cursos técnicos ofertados pelo Ministério da Educação, existe apenas um curso técnico para saneamento e um para técnico em sistemas de energia renovável, não havendo uma formação específica para o tema "biogás de ETEs". Outro aspecto relevante é que a capacitação do setor de saneamento no Brasil é pouco estruturada, de forma que não há um padrão sobre as competências e habilidades necessárias para a função de operação de ETEs.

Nesse contexto, o objetivo geral desta nota técnica é reportar os resultados provenientes da estruturação de um processo de capacitação sobre aproveitamento energético de biogás de ETEs, adaptado às condições brasileiras e com potencial de replicação, o qual foi desenvolvido no âmbito do PROBIOGÁS. O documento tem como objetivos específicos: apresentar a demanda nacional sobre capacitação na área supracitada, propor uma grade curricular que oriente o processo de capacitação no tema em questão no Brasil e analisar os resultados de um projeto de transferência de conhecimento realizado no estado do Paraná. 


\section{METODOLOGIA}

O desenvolvimento do processo de capacitação sobre aproveitamento energético de biogás de ETEs seguiu três etapas:

a) Definição da estratégia e da demanda nacional de capacitação;

b) Capacitação dos multiplicadores e elaboração da grade curricular e dos projetos de transferência do conhecimento;

c) Implementação do projeto de transferência de conhecimento no estado do Paraná.

\subsection{Definição da estratégia e da demanda nacional de capacitação}

Para a elaboração da estratégia de capacitação, selecionaram-se 14 profissionais especializados em educação profissional no setor de saneamento. Esses profissionais fizeram uma viagem à Alemanha com duração de 1 semana, para visitar centros de educação e para discutirem o tema, de forma a adaptar os conceitos alemães às especificidades brasileiras. As instituições participantes dessa delegação são apresentadas na Tabela I.

Tabela I: Instituições participantes da definição da estratégia de capacitação

\begin{tabular}{|c|c|}
\hline Setor & Instituição \\
\hline \multirow{10}{*}{ Academia } & Fundação Escola de Sociologia e Política de São Paulo - FESPSP \\
\hline & Instituto Federal de Brasília - IFB \\
\hline & Núcleo Regional do Sudeste - NUCASE*/ Universidade Federal de Minas Gerais -- UFMG \\
\hline & Núcleo Regional do Nordeste - NURENE*/ Universidade Federal da Bahia - UFBA \\
\hline & Centro de Tecnologia do Gás e Energias Renováveis - CTGÁS-ER \\
\hline & Universidade do Vale do Rio dos Sinos - UNISINOS \\
\hline & SENAI-DN (Departamento Nacional) \\
\hline & SENAI-RS (Rio Grande do Sul) \\
\hline & Universidade de Caxias do Sul - UCS \\
\hline & Universidade Federal de Goiás - UFG \\
\hline \multirow{7}{*}{ Alemanha } & Centro de Gerenciamento de Resíduos Pohlsche Heide \\
\hline & Centro Nacional Alemão de Pesquisa e Formação na Gestão de Recursos e Resíduos Sólidos - CreED \\
\hline & ETE Kassel \\
\hline & ETE Witzenhausen \\
\hline & GIZ Alemanha \\
\hline & Parque Industrial Frankfurt-Höchst \\
\hline & TU Nordhausen \\
\hline \multirow{2}{*}{ Governo } & Ministério das Cidades \\
\hline & GIZ \\
\hline \multirow{2}{*}{ Saneamento } & Associação Brasileira de Engenharia Sanitária e Ambiental - ABES \\
\hline & Associação Nacional dos Serviços Municipais de Saneamento - ASSEMAE \\
\hline
\end{tabular}

$\mathrm{Na}$ oportunidade, dentre outras instituições, visitou-se uma instituição de educação (TU Nordhausen), duas ETEs com aprendizes no sistema dual ${ }^{1}$ (ETE Kassel e ETE Witzenhausen) e um centro de pesquisa (CReED). Essas visitas disponibilizaram elementos para a discussão e, ao final do processo, o grupo definiu a estratégia de capacitação para os diferentes atores do setor de saneamento brasileiro, conforme apresentado na Figura I.

\footnotetext{
${ }^{1} \mathrm{O}$ sistema dual de formação profissional é o tipo de formação mais prático na Alemanha, no qual há uma combinação entre a formação prática, dentro de uma empresa, e a formação teórica, em uma escola profissional. Mais informações: https://www.deutschland.de/pt/topic/ conhecimento/educacao-aprendizagem/sistema-dual-de-formacao-profissional.
} 
Como o tema de aproveitamento energético de biogás é relativamente novo no Brasil, entendeu-se que todos os níveis de profissionais do setor de saneamento necessitam de alguma forma de capacitação. Os profissionais foram divididos em 3 (três) grupos: (1) Políticos, Gestores e Tomadores de decisão que, no entendimento da delegação, necessitavam, principalmente, de eventos de sensibilização (workshops e seminários), bem como de cursos mais específicos de curta duração (formação continuada); (2) Profissionais com nível superior, principalmente engenheiros e projetis- tas, que podem se especializar por meio de cursos de formação continuada e da participação no processo de formação de multiplicadores, que além da capacitação dos profissionais, visa elaborar uma grade curricular sobre o tema para servir de base às instituições de ensino; e (3) Profissionais tecnólogos e com nível técnico ou inferior, principalmente operadores de ETEs com experiência na área, que necessitam de uma maior capacitação, a partir da participação em cursos de formação continuada e dos cursos gerados a partir da formação de multiplicadores e da grade curricular.

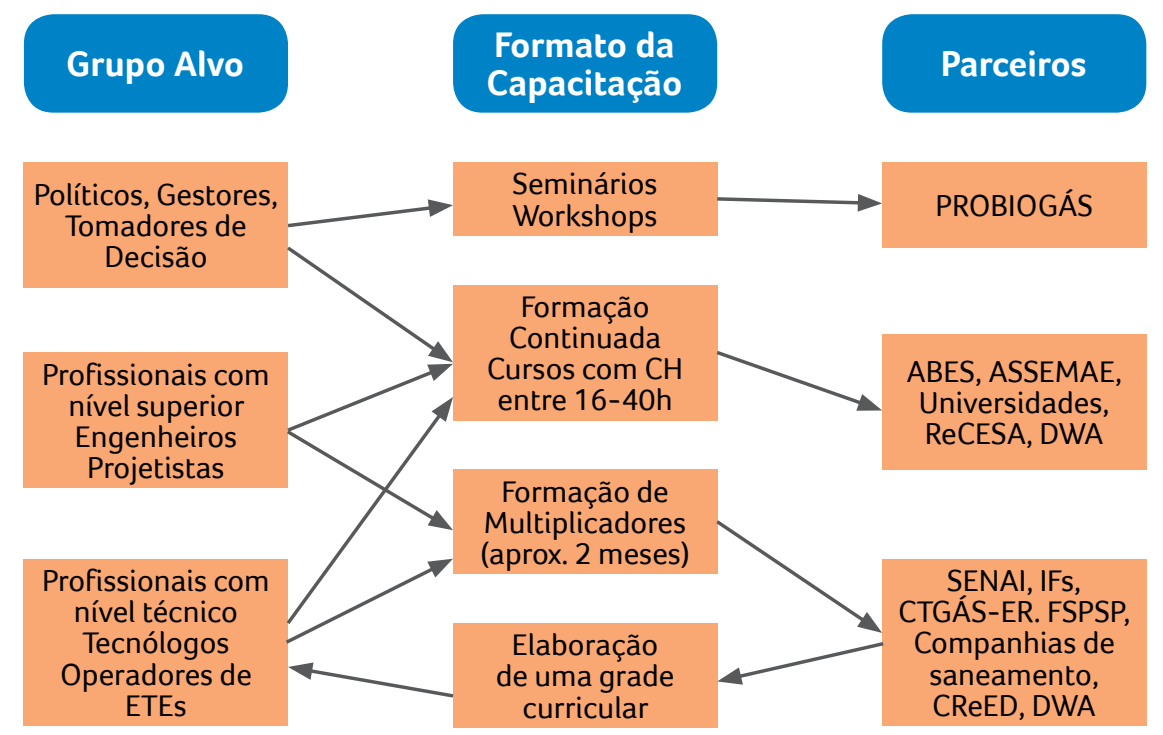

Figura I. Estratégia de capacitação para o setor de tratamento de esgotos

Após o delineamento da estratégia de capacitação, realizou-se uma pesquisa por demanda de capacitação na área de operação de ETEs com aproveitamento energético de biogás. Essa pesquisa foi disseminada pelo Ministério das Cidades para as prestadoras de serviços de esgotamento sanitário que atendem a uma população equivalente acima de 50.000 habitantes, em 55 municípios, totalizando 31 prestadores de serviços. Os entrevistados foram indagados sobre a quantidade de profissionais interessados em participar do processo de capacitação. Portanto, os resultados dessa pesquisa totalizaram a demanda atual por capacitação na área.

\subsection{Capacitação dos multiplicadores e elaboração da grade curricular e dos projetos de transferência do conhecimento}

A formação de multiplicadores foi estruturada com o objetivo de capacitar profissionais da academia e especialistas em tratamento de esgoto, além de desenvolver uma grade curricular sobre a operação de plantas de biogás de ETEs brasileiras. Para que essa grade curricular atendesse à real demanda do setor de saneamento, prestadores de serviços de saneamento também foram convidados a participar da capacitação. Ambas as ações visaram garantir a disseminação do conhecimen- 
to do tema no país, tendo em vista que projetos de referência surgirão no médio e longo prazos, e necessitarão de mão de obra qualificada para serem bem-sucedidos.

O processo de capacitação dos multiplicadores foi definido por um segundo grupo de profissionais alemães e brasileiros, de forma a conciliar a experiência alemã nesse tipo de atividade e o conhecimento dos profissionais brasileiros sobre o setor de saneamento e os perfis dos atores envolvidos. Pelo lado alemão, a condução desse processo foi realizada por profissionais da $D_{W A}^{2}$, experientes no processo de capacitação de multiplicadores e elaboração de grades curriculares no setor de saneamento. Já o lado brasileiro pode contribuir mais profundamente no conteúdo técnico necessário a esses atores e na validação das propostas metodológicas, contando com apoio de profissionais que constituíram o ReCESA.

A formação foi, então, estruturada em 4 etapas: (1) workshop introdutório; (2) treinamento teórico e prático; (3) workshop de follow-up; e (4) treinamento piloto.

O workshop introdutório foi realizado na ETE de Ribeirão Preto, localizada no município de Ribeirão Preto - SP, que aproveita energeticamente o biogás gerado a partir da digestão anaeróbia do lodo. Essa etapa teve como objetivo principal o nivelamento de informações sobre as questões operacionais de uma estação de tratamento de esgoto.

O treinamento teórico e prático, com duração de 3 semanas, foi realizado na Alemanha, nos municípios de Hamburg e Hennef, e contou com aulas em ETEs, laboratórios e centros da DWA em Hamburg e Hennef. Esse treinamento teve como objetivo a absorção de novos conhecimentos pelos participantes sobre o tratamento de esgoto e aproveitamento energético de biogás na teoria e na prática e sobre aspectos didáticos e pedagógicos, bem como a elaboração de uma grade curricular sobre o tema para servir de base a instituições de ensino brasileiras para criação de cursos. A elaboração da grade curricular contou com a experiência alemã e foi definida em outras 3 etapas: (1) definição do perfil dos participantes dos futuros cursos criados a partir da grade; (2) definição das habilidades e competências que esses profissionais necessitam após a finalização dos cursos e (3) definição dos macroconteúdos necessários nos cursos para desenvolver as habilidades e competências definidas na etapa anterior.

O workshop de follow-up foi realizado em Brasília-DF, com o objetivo de detalhar o conteúdo de uma grade curricular inédita, que foi discutida na Alemanha, e preparar os participantes para o treinamento piloto, por meio da elaboração dos planos de aula.

Por fim, o treinamento piloto foi realizado no Rio de Janeiro-RJ, com duração de 5 dias, com o objetivo de colocar em práticas as metodologias aprendidas e trocar experiências com profissionais do setor. A Tabela ll apresenta a carga horária e o local de cada uma dessas etapas.

Tabela II: Carga horária e local de cada etapa da formação de multiplicadores

\begin{tabular}{|l|c|c|}
\hline Etapa & Carga Horária & \multicolumn{1}{|c|}{ Local } \\
\hline Workshop introdutório & 1 dia (8 horas) & Ribeirão Preto/SP \\
\hline Treinamento teórico e prático & $\begin{array}{c}15 \text { dias (120 } \\
\text { horas) }\end{array}$ & $\begin{array}{c}\text { Hamburg } \\
\text { e Hennef/ } \\
\text { Alemanha }\end{array}$ \\
\hline Workshop de follow-up & 2 dias (16 horas) & Brasília/DF \\
\hline Treinamento piloto & 5 dias (40 horas) & Rio de Janeiro/RJ \\
\hline
\end{tabular}

\footnotetext{
${ }^{2}$ A DWA (Associação Alemã para Águas, Efluentes e Resíduos) é uma associação técnica com definições nas áreas de esgoto e gerenciamento das águas, para cerca de 300 treinamentos e 35.000 participantes por ano e para informar os 14.000 profissionais do setor de águas alemão. No escritório nacional e nas sete regionais trabalham ao todo 140 profissionais. A DWA atua intensivamente em parceria com associações nacionais e internacionais. A associação desenvolve projetos internacionais da GIZ e de outras instituições com transferência dos conceitos alemães para o exterior, principalmente nas áreas de normatização, formação profissional, certificação e organização do setor por meio das associações civis. Em Hennef, encontram-se a maior biblioteca sobre gerenciamento de águas e algumas salas de treinamento e de conferência.
} 
Para participar dessa capacitação, elaborou-se um edital de seleção de profissionais. Esse edital solicitava o envio de um currículo acadêmico e profissional, uma carta de motivação e uma proposta de projeto de transferência de conhecimento. Além disso, todos os candidatos deveriam enviar um termo de compromisso assinado pelo candidato e por um representante da instituição, de forma a garantir minimamente um compromisso institucional. Disponibilizaram-se 10 vagas para o setor acadêmico, 5 vagas para prestadores de serviços de esgotamento sanitário e 1 vaga para o Ministério das Cidades. 0 processo de candidatura ficou aberto no período de 29/04/2014 a 30/05/2014.

Receberam-se 37 candidaturas, sendo 19 candidaturas de profissionais de instituições de ensino, 17 de prestadores de serviços (10 estaduais, 6 municipais e 1 privada) e 1 do Ministério das Cidades.

Um corpo técnico de 5 profissionais do PROBIOGÁS avaliou as candidaturas de acordo com o conhecimento prévio dos candidatos com relação ao tema (esgotamento sanitário e aproveitamento energético de biogás), a experiência com capacitação, a motivação para participar do processo e o alcance e profundidade do projeto de transferência de conhecimento. A Tabela III apresenta as instituições selecionadas para participar do processo de capacitação de multiplicadores.

Tabela III: Instituiç̧̃es participantes do processo de capacitação de multiplicadores

\begin{tabular}{|c|l|c|}
\hline \multirow{3}{*}{ Setor } & Instituição & Número de participantes \\
\hline \multirow{4}{*}{ Academia } & CTGÁS-ER & 1 \\
\cline { 2 - 3 } & FESPSP & 1 \\
\cline { 2 - 3 } & IFB & 3 \\
\cline { 2 - 3 } & SENAI-ES & 1 \\
\cline { 2 - 3 } & SENAI-PR & 1 \\
\cline { 2 - 3 } & SENAI-RS & 1 \\
\hline \multirow{5}{*}{ Saneamento } & SENAI-SC & 1 \\
\cline { 2 - 3 } & SENAI-SP & 1 \\
\hline & Embient & 1 \\
\cline { 2 - 3 } & EMBASA & 2 \\
\cline { 2 - 3 } & SANASA & 1 \\
\cline { 2 - 3 } & SeMAE SJRP & 1 \\
\hline \multirow{5}{*}{ Governo } & Ministério das Cidades & 1 \\
\hline
\end{tabular}

As instituições selecionadas apresentaram uma proposta prévia de um projeto de transferência do conhecimento, basicamente relacionadas a treinamentos de curta duração ou a inclusão de matérias e cursos em sua instituição de ensino. Na Tabela IV, listam-se os projetos de transferência propostos por cada instituição.

Tabela IV: Projetos de transferência de conhecimento propostos pelas instituições selecionadas

\begin{tabular}{|c|c|c|}
\hline Setor & Instituição & Projeto de transferência \\
\hline \multirow{7}{*}{$\begin{array}{l}\text { Treinamento } \\
\text { de curta } \\
\text { duração } \\
(<=40 \mathrm{~h})\end{array}$} & Ambient & Treinamento com visita técnica na ETE \\
\hline & EMBASA & \multirow{3}{*}{ Multiplicação interna } \\
\hline & MCID & \\
\hline & SANASA & \\
\hline & SeMAE SJRP & $\begin{array}{l}\text { Multiplicação interna e curso para } \\
\text { operadores de ETEs }\end{array}$ \\
\hline & SENAI-PR & $\begin{array}{l}\text { Capacitação de operadores da } \\
\text { SANEPAR }\end{array}$ \\
\hline & SENAI-RS & $\begin{array}{l}\text { Multiplicação interna, sensibilização e } \\
\text { capacitação de operadores de ETEs }\end{array}$ \\
\hline \multirow{6}{*}{$\begin{array}{l}\text { Inclusão de } \\
\text { matérias e } \\
\text { cursos na } \\
\text { instituição }\end{array}$} & SENAI-SP & $\begin{array}{l}\text { Inclusão de disciplinas em cursos } \\
\text { existentes }\end{array}$ \\
\hline & FESPSP & \multirow{2}{*}{$\begin{array}{l}\text { Multiplicação interna, inclusão de } \\
\text { disciplinas em cursos existentes e } \\
\text { criação de novos cursos }\end{array}$} \\
\hline & IFB & \\
\hline & CTGÁS-ER & Multiplicação interna e criação de curso \\
\hline & SENAI-ES & $\begin{array}{l}\text { Multiplicação interna, inclusão de } \\
\text { disciplinas em cursos existentes, } \\
\text { criação de novos cursos e consultoria a } \\
\text { empresas }\end{array}$ \\
\hline & SENAI-SC & $\begin{array}{l}\text { Inclusão de disciplinas em cursos } \\
\text { existentes e criação de novos cursos }\end{array}$ \\
\hline
\end{tabular}

\subsection{Implementação do projeto de transferência de conhecimento no estado do Paraná}

O SENAI-PR, instituição com experiência em capacitação profissional na área de saneamento, desenvolveu um projeto de transferência de conhecimento em parceria com a Companhia de Saneamento do Paraná - Sanepar. A Sanepar foi escolhida por apresentar um alto potencial para a multiplicação dos conhecimentos de biogás a serem adquiridos pelos profissionais capacitados, já que a empresa conta com mais de 200 ETEs com produção de biogás, sendo referência nacional no setor de saneamento.

O projeto capacitou 100 profissionais da Sanepar distribuídos em cinco turmas, as quais foram treinadas nos anos de 2015 e 2016. 
A estrutura metodológica dessa capacitação limitou o número de participantes por turma em 25 pessoas, visando garantir a troca de experiências e a qualidade das dinâmicas propostas. Já a carga horária e os conteúdos a serem apresentados foram elaborados com base nas principais tecnologias de tratamento de esgotos utilizadas no Brasil, bem como nos possíveis arranjos para aproveitamento energético de biogás nestas ETEs.

As aulas foram montadas utilizando apresentação de slides, vídeos e atividades práticas com cartões magnéticos (desenvolvidos pela DWA). Essa última ferramenta consiste em cartões magnéticos que são utilizados para a confecção de fluxogramas de ETEs com aproveitamento de biogás, permitindo que os alunos identifiquem: a) as sequências lógicas do processo; b) as possíveis alternativas de arranjos para aproveitamento energético; c) os possíveis locais na ETE com a possibilidade de melhorias para receber a tecnologia de aproveitamento de biogás; d) os equipamentos necessários para tal.

Para a avaliação do curso, entregou-se aos participantes, no início do primeiro dia do treinamento, um questionário para avaliar o grau de concordância dos participantes quanto ao estado da arte e a importância do aproveitamento energético de biogás em ETEs. O mesmo questionário foi aplicado novamente ao final do último dia do treinamento, visando avaliar possíveis mudanças de percepção sobre o assunto.

Além da avaliação pré e pós-curso, realizou-se uma avaliação que incorporava os temas: conteúdo, métodos, instrutor, organização do evento e infraestrutura.

\section{RESULTADOS E DISCUSSÕES}

\subsection{1 Demanda por capacitação no Brasil}

A Figura ll sumariza os resultados da pesquisa de demanda, informando o número de profissionais que precisariam ser capacitados em cada estado. As manifestações de interesse por capacitação foram registradas em quatro regiões do país. Identificou-se que há uma demanda por capacitação de, pelo menos, 691 profissionais, majoritariamente localizada no Distrito Federal e nos estados da Bahia, de São Paulo e do Paraná.

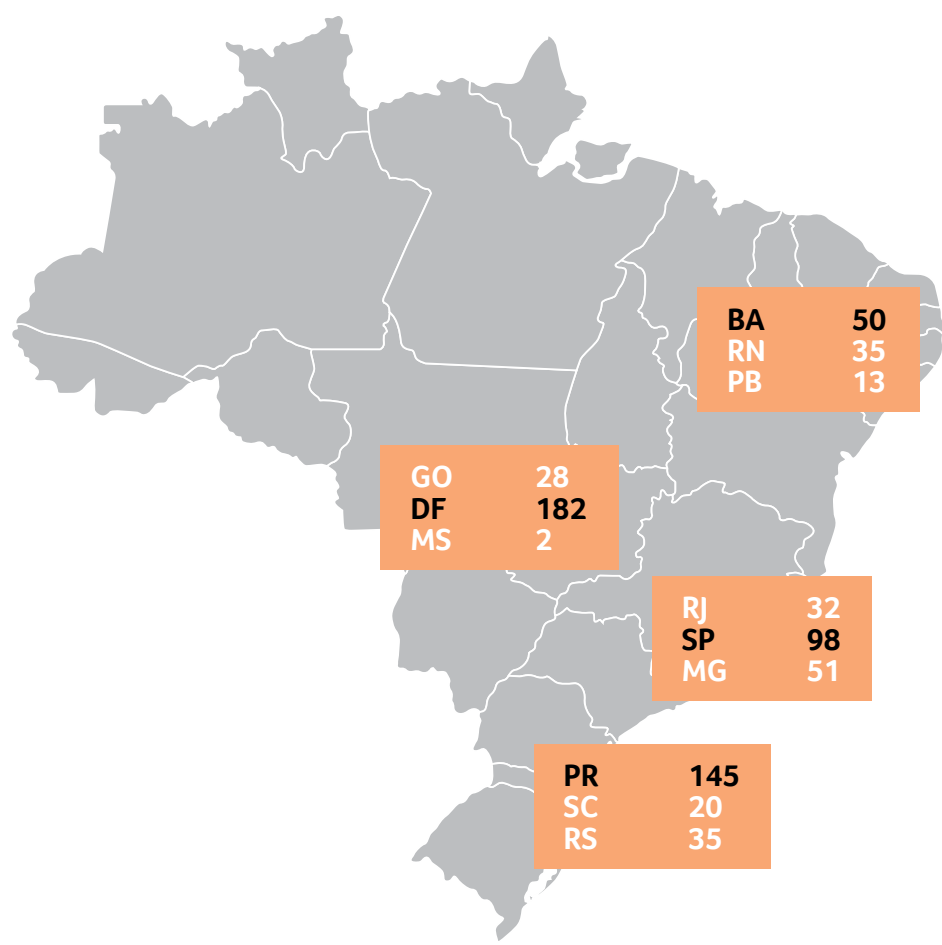

Figura II. Demanda por capacitação de profissionais na área de aproveitamento energético de biogás de ETEs no Brasil 


\subsection{Elaboração da grade curricular e dos projetos de transferência de conhecimento}

Durante todas as quatro etapas de capacitação de multiplicadores, mas principalmente durante o treinamento teórico e prático, os participantes trabalharam para definir bases para uma grade curricular que atendesse à demanda do setor. $O$ perfil do operador que atenderia a um curso baseado nessa grade, ou seja, o público-alvo, foi definido como: (1) maiores de 18 anos; (2) com ensino médio com- pleto; (3) com experiência prática na operação de tratamento de esgotos (acima de 2 anos).

A partir desse perfil, os multiplicadores definiram as habilidades e competências necessárias para os operadores de uma ETE com aproveitamento energético de biogás. A Tabela $V$ apresenta as habilidades e competências definidas pelos multiplicadores como sendo as necessárias para a operação de ETEs com aproveitamento energético de biogás.

Tabela V: Competências e habilidades necessárias para operadores de ETEs brasileiras com aproveitamento energético de biogás

\begin{tabular}{|c|c|}
\hline Competências & Habilidades \\
\hline $\begin{array}{l}\text { Operacionalizar e coordenar os procedimentos de } \\
\text { coleta e análise de amostras }\end{array}$ & $\begin{array}{l}\text { Conhecer metodologias de coleta de amostras e padrões de qualidade, segurança e saúde } \\
\text { Interpretar os resultados das análises } \\
\text { Realizar procedimentos analíticos básicos e instrumentais }\end{array}$ \\
\hline $\begin{array}{l}\text { Operar, orientar a operação e verificar os instrumentos } \\
\text { de medição e controle }\end{array}$ & $\begin{array}{l}\text { Coletar dados operacionais em campo } \\
\text { Preencher e interpretar relatórios operacionais } \\
\text { Operar funções básicas dos sistemas supervisórios e instrumentos de medição e controle }\end{array}$ \\
\hline $\begin{array}{l}\text { Orientar a operação e manutenção dos equipamentos } \\
\text { eletromecânicos da ETE e da linha de gás }\end{array}$ & $\begin{array}{l}\text { Avaliar e garantir a correta operação dos equipamentos da ETE e da linha de gás } \\
\text { Realizar práticas de manutenção preventiva } \\
\text { Acionar bombas, compressores e motores e avaliar a necessidade de manutenção ou substituição } \\
\text { Operar quadros de comando }\end{array}$ \\
\hline $\begin{array}{l}\text { Operacionalizar e controlar os sistemas anaeróbios e } \\
\text { de geração de gás }\end{array}$ & $\begin{array}{l}\text { Compreender os processos microbiológicos e parâmetros de operação } \\
\text { Perceber, avaliar e agir em resposta à possíveis anomalias no sistema } \\
\text { Interpretar fluxogramas do processo e identificar seus pontos críticos } \\
\text { Utilizar ferramentas básicas de informática na análise e acompanhamento de dados operacionais }\end{array}$ \\
\hline $\begin{array}{l}\text { Coordenar a rotina de verificação, aferição e calibração } \\
\text { de sensores }\end{array}$ & $\begin{array}{l}\text { Manipular instrumentos de precisão delicados } \\
\text { Atualizar e monitorar os registros de resultados de calibração } \\
\text { Entender conceitos de erros e imprecisões e saber identificar necessidade de calibração } \\
\text { Realizar análise crítica dos resultados de calibração e aferição }\end{array}$ \\
\hline $\begin{array}{l}\text { Supervisionar, verificar e monitorar os componentes } \\
\text { das instalações de geração de energia }\end{array}$ & $\begin{array}{l}\text { Supervisionar equipes no manuseio de equipamentos } \\
\text { Utilizar ferramentas e instrumentos de medição da linha de gás } \\
\text { Inspecionar e monitorar componentes e equipamentos das instalações de geração de energia } \\
\text { Monitorar e executar testes conforme padrão de qualidade, saúde e segurança nos equipamentos } \\
\text { Interpretar os processos operacionais e seus limites } \\
\text { Utilizar interfaces e funcionalidade do software supervisório } \\
\text { Elaborar e interpretar relatório de controle operacional }\end{array}$ \\
\hline $\begin{array}{l}\text { Realizar e monitorar os serviços de manutenção e } \\
\text { limpeza das unidades de biogás }\end{array}$ & $\begin{array}{l}\text { Elaborar procedimentos de limpeza } \\
\text { Coordenar a periodicidade de limpeza e manutenção de equipamentos }\end{array}$ \\
\hline $\begin{array}{l}\text { Orientar quanto a normas de QSMS e garantir seu } \\
\text { cumprimento }\end{array}$ & $\begin{array}{l}\text { Reconhecer os riscos reais e potenciais referentes às atividades operacionais } \\
\text { Identificar e reconhecer a importância do uso de equipamentos de proteção individual (EPIs) e } \\
\text { coletiva (EPCs) para a realização de suas atividades } \\
\text { Identificar as medidas preventivas e corretivas } \\
\text { Entender a importância da prevenção/remediação de impactos ao meio ambiente }\end{array}$ \\
\hline
\end{tabular}

Um aspecto importante dessa definição é a especificidade do público-alvo, que detém bons conhecimentos práticos sobre os assuntos a serem abordados no curso. Essa característica exige do educador uma abordagem transversal do conhecimento, ou seja, o educador deve entender que os conhecimentos práticos dos participantes são de grande valia e devem ser utilizados durante o curso, mas contextualizados com conhecimentos teóricos. Dessa forma, o itinerário formativo deve ser orientado à prática e se estrutura em (1) identificação dos conceitos-chave; (2) teorização - alternativas e soluções; (3) retorno à realidade para validação das teorias.

Com as competências e habilidades definidas, os multiplicadores definiram os macroconteúdos necessários a serem abordados em um curso para desenvolver essas capacidades. Esses macroconteúdos foram divididos em 9 (nove) módulos, conforme apresentado na Tabela VI. 
Tabela VI: Módulos da grade curricular e seus respectivos macroconteúdos

\begin{tabular}{|c|c|}
\hline Módulo & Macroconteúdos \\
\hline $\begin{array}{l}\text { 1. Sistemas de esgoto, processos de tratamento, } \\
\text { geração e aproveitamento de biogás }\end{array}$ & $\begin{array}{l}\text { Aspectos de trabalho em equipe } \\
\text { Contextualização do saneamento no Brasil, organização do setor e marco regulatório } \\
\text { Contextualização do biogás na matriz energética } \\
\text { Noções sobre os processos de tratamento de esgoto } \\
\text { Noções sobre geração de gás no tratamento de esgoto e lodo } \\
\text { Noções da importância, perigos e impactos ambientais do biogás } \\
\text { Noções de geração de energia a partir do biogás }\end{array}$ \\
\hline 2. Controle de qualidade do tratamento de esgoto & $\begin{array}{l}\text { Sistemas de unidades de medidas e conversões } \\
\text { Noções de química e microbiologia } \\
\text { Noções de análises físico-químicas e biológicas } \\
\text { Padrões de qualidade no tratamento de esgoto } \\
\text { Parâmetros de avaliação de desempenho e controle operacional } \\
\text { Redação técnica } \\
\text { Tipos de amostras e técnicas de amostragem } \\
\text { Noções de parâmetros de qualidade do biogás relacionados ao tratamento de esgoto }\end{array}$ \\
\hline 3. Instrumentos de medição e controle em ETEs & $\begin{array}{l}\text { Instrumentos, métodos e equipamentos de medição } \\
\text { Noções básicas de ferramentas de informática } \\
\text { Apresentação de softwares supervisórios } \\
\text { Interpretação de resultados das medições } \\
\text { Redação técnica }\end{array}$ \\
\hline $\begin{array}{l}\text { 4. Funcionamento e manutenção de componentes e } \\
\text { equipamentos eletromecânicos }\end{array}$ & $\begin{array}{l}\text { Noções de termodinâmica } \\
\text { Equipamentos eletromecânicos do tratamento de esgoto e geração de energia } \\
\text { Tubulações, acessórios, flanges, isolamentos, bombas, válvulas e compressores } \\
\text { Práticas de manutenção preventiva, preditiva e corretiva } \\
\text { Noções de segurança em sistemas pressurizados e atmosferas explosivas }\end{array}$ \\
\hline 5. Produção e monitoramento de biogás em ETEs & $\begin{array}{l}\text { Ferramentas de informática } \\
\text { Equipamentos e componentes do sistema e instrumentos de controle } \\
\text { Noções do processo anaeróbio e de geração de gás } \\
\text { Variáveis do processo de geração de gás e seu controle } \\
\text { Softwares supervisórios } \\
\text { Redação técnica } \\
\text { Fluxogramas dos processos }\end{array}$ \\
\hline 6. Aferição e calibração de sensores & $\begin{array}{l}\text { Sensores e a importância de aferição e calibração } \\
\text { Noções de metrologia } \\
\text { Variáveis e métodos de aferição e calibração }\end{array}$ \\
\hline 7. Tratamento e uso final do biogás & $\begin{array}{l}\text { Composições do biogás e características dos diferentes gases } \\
\text { Diferentes usos do biogás e seus requisitos } \\
\text { Noções de processos de armazenamento e tratamento de gases } \\
\text { Instrumentos e equipamentos de medição } \\
\text { Softwares supervisórios e de automação }\end{array}$ \\
\hline 8. Manutenção e limpeza das unidades de biogás & $\begin{array}{l}\text { Equipamentos e suas necessidades de limpeza e manutenção } \\
\text { Produtos químicos, agentes de desinfecção e seus usos } \\
\text { Noções básicas de processos mecânicos de limpeza e seus materiais } \\
\text { Ferramentas de manutenção e limpeza } \\
\text { Vantagens da realização de manutenção e limpeza e consequências da não realização }\end{array}$ \\
\hline $\begin{array}{l}\text { 9. Qualidade, segurança, meio ambiente } \\
\text { e saúde-QSMS }\end{array}$ & $\begin{array}{l}\text { Legislação e normas aplicáveis } \\
\text { Riscos e perigos no tratamento de esgoto e na produção de biogás } \\
\text { Procedimentos básicos de mitigação de riscos e perigos } \\
\text { Noções de aspectos e impactos ambientais } \\
\text { Atendimento a emergências ambientais } \\
\text { Noções de segurança operacional, EPIs e EPCs } \\
\text { Noções sobre procedimentos de primeiros socorros } \\
\text { Aspectos e padrões de qualidade do processo de tratamento de esgoto e de geração de energia }\end{array}$ \\
\hline
\end{tabular}

Esses módulos e macroconteúdos podem ser divididos em 3 grandes blocos de conhecimentos: (1) Área de contextualização, na qual constam temas mais amplos e imprescindíveis para o entendimento das atividades desempenhadas pelo profissional do setor; (2) Área métodos e meios, que apresenta métodos, recursos, ferramentas e seus funcionamentos necessários para as atividades do profissional e; (3) Área fim, que contém os módulos, cujos temas são mais específicos. A Figura III ilustra essas áreas e os módulos pertencentes a cada uma delas. 


\author{
ÁREA DE CONTEXTUALIZAÇÃO \\ 1. Sistema de esgoto, processos de \\ tratamento, geraçăo $e$ \\ aproveitamento de biogás \\ 2. Controle de qualidade no \\ tratamento de esgoto
}

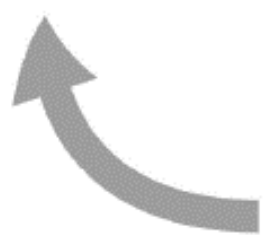

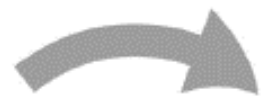

\section{ÁREA MATERIAIS E MEIOS}

3. Instrumentos de mediçăo e controle em ETEs

4. Funcionamento e manutenção de componentes e equipamentos eletromecânicos

\section{Calibraçāo de sensores}

\section{ÁREA FIM}

6. Produçăo e monitoramento de biogás em ETEs

7. Tratamento e uso final do biogás

8. Manutençăo e limpeza das unidades de biogás

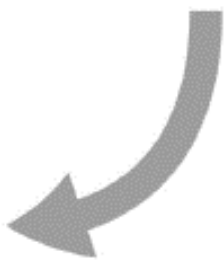

9. Qualidade, Segurança, Meio ambiente e Saúde - QSMS

Figura III. Áreas de conhecimento da grade curricular

Utilizando-se da metodologia apresentada, os multiplicadores definiram para cada módulo (1) objetivo geral; (2) mensagens-chave, que são as principais ideias que devem se repetidas durante o módulo; (3) pré-requisitos; (4) objetivos específicos; (5) carga horária estimada, que pode ser alterada de acordo com as necessidades específicas do público-alvo regional; e (6) sugestões de materiais e recursos pedagógicos para serem utilizados nas aulas. Essa grade curricular, além de servir como base para a transferência de conhecimento dos multiplicadores, está sendo discutida em um grupo de trabalho do Comitê Temático em Formação Profissional em Energias Renováveis e Eficiência Energética do Ministério da Educação - MEC, que visa estruturar novos cursos sobre esse tema dentro da Rede Federal de Educação Profissional, Científica e Tecnológica.

\subsection{Projeto de transferência do conhecimento no estado do Paraná: SENAI-PR e Sanepar} O projeto de transferência entre SENAI-PR e Sanepar foi elaborado com uma carga horária de $40 \mathrm{~h}$, dividas em $8 \mathrm{~h}$ ao longo de 5 dias seguidos, sendo intitulado "Aproveitamento energético de biogás em ETEs". As aulas foram realizadas na sede administrativa da Sanepar em Curitiba-PR. A Tabela VII apresenta o conteúdo abordado durante o curso. 
Tabela VII: Conteúdos abordados no projeto de transferência intitulado "Aproveitamento energético de biogás em ETEs", realizado pelo SENAI-PR com a Sanepar.

\begin{tabular}{|c|l|}
\hline Dia & Conteúdo \\
\hline 1 & $\begin{array}{l}\text { Apresentação do curso; Cenário nacional energético e do saneamento; Premissas para o uso de biogás no setor de saneamento; Características } \\
\text { físico-químicas do esgoto; Degradação aeróbia x anaeróbia; Fases da degradação anaeróbia (hidrólise, acidogênese, acetogênese, metanogênese). }\end{array}$ \\
\hline 2 & $\begin{array}{l}\text { Inibidores do metabolismo e da produção de biogás: } \mathrm{pH} \text {, acidez, alcalinidade, Nitrogênio amoniacal, frações de enxofre, altura do manto de lodo, } \\
\text { tempo de detenção e caminhos preferenciais; Características físico-químicas do biogás: } \mathrm{CH}_{4}, \mathrm{CO}_{2}, \mathrm{NH}_{3}, \mathrm{H}_{2} \mathrm{~S}_{2}, \mathrm{~N}_{2}, \mathrm{O}_{2}, \text { siloxanos, umidade. Produção de } \text { biogás em reatores UASB e digestores de lodo. }\end{array}$ \\
\hline 3 & $\begin{array}{l}\text { Tratamento do biogás: condensadores, lavadores de gás, filtros de carvão, filtros dessulfurizadores; Estratégias de monitoramento do processo } \\
\text { em digestores de lodo e reatores UASB; Ações corretivas e preventivas para manutenção da produção eficiente de biogás em digestores de lodo e } \\
\text { reatores UASB; Instrumentação e automação para biogás. }\end{array}$ \\
\hline 4 & $\begin{array}{l}\text { Segurança na operação das plantas de biogás: limite inferior e superior de explosão, mínimo de energia de ignição, atmosfera explosiva, risco de } \\
\text { explosão, áreas classificadas, proteção contra explosão (sensores e equipamentos categorias 1, 2 e 3); Arranjos para aproveitamento energético: } \\
\text { elétrico, térmico, cogeração, térmico e elétrico; Cálculos de produção de biogás, aproveitamento de energia elétrica e térmica (modelo matemático } \\
\text { de Lobato 2011 e ProBio 1.0). }\end{array}$ \\
\hline 5 & $\begin{array}{l}\text { Geração de energia elétrica: motogeradores ciclo Otto, microturbinas a gás, equipamentos necessários à sincronia com a rede elétrica; Geração de } \\
\text { energia térmica: secadores de lodo (tambores rotativos e leitos fluidizados); Qualidade necessária aos materiais nas ETEs com aproveitamento de } \\
\text { biogás: equipamentos, tubulações, estruturas, isolamento térmico e proteção contra corrosão; Pesquisas desenvolvidas pela Sanepar. }\end{array}$ \\
\hline
\end{tabular}

A avaliação de percepção dos participantes do curso quanto ao estado da arte e importância do aproveitamento energético de biogás em ETEs foi realizada com base nos aspectos: 1) critérios de gestão financeira e fatores na tomada de decisões para investimentos; 2) melhorias nas condições de trabalho e, por fim, 3) alterações na operação das ETEs. Nessas avaliações, de um universo de 100 alunos, apenas 76 pré e pós-avaliações puderam ser utilizadas. As demais não foram entregues ou apresentaram problemas como respostas ilegíveis ou incompletas.

A Figura IV mostra a percepção dos participantes quanto aos critérios de gestão financeira, na qual nota-se que a maioria dos participantes, embora consi- derem que para o aproveitamento de biogás em ETEs o investimento necessário seja elevado, tanto na pré como na pós avaliação, em média $66 \%$ consideram que essa estratégia apresenta um retorno financeiro que "compensa" o investimento. Quanto a aumentar a eficiência das ETEs, notou-se um aumento de 42 para $66 \%$ na pós avaliação, em que as pessoas concordaram plenamente que essa alternativa é importante e deve ser levada como fator na tomada de decisões para a implementação da tecnologia anaeróbia. Essa importância foi apontada como estratégica para negócios e teve concordância plena de $65 \%$ das pessoas tanto na pré como na pós-avaliação.

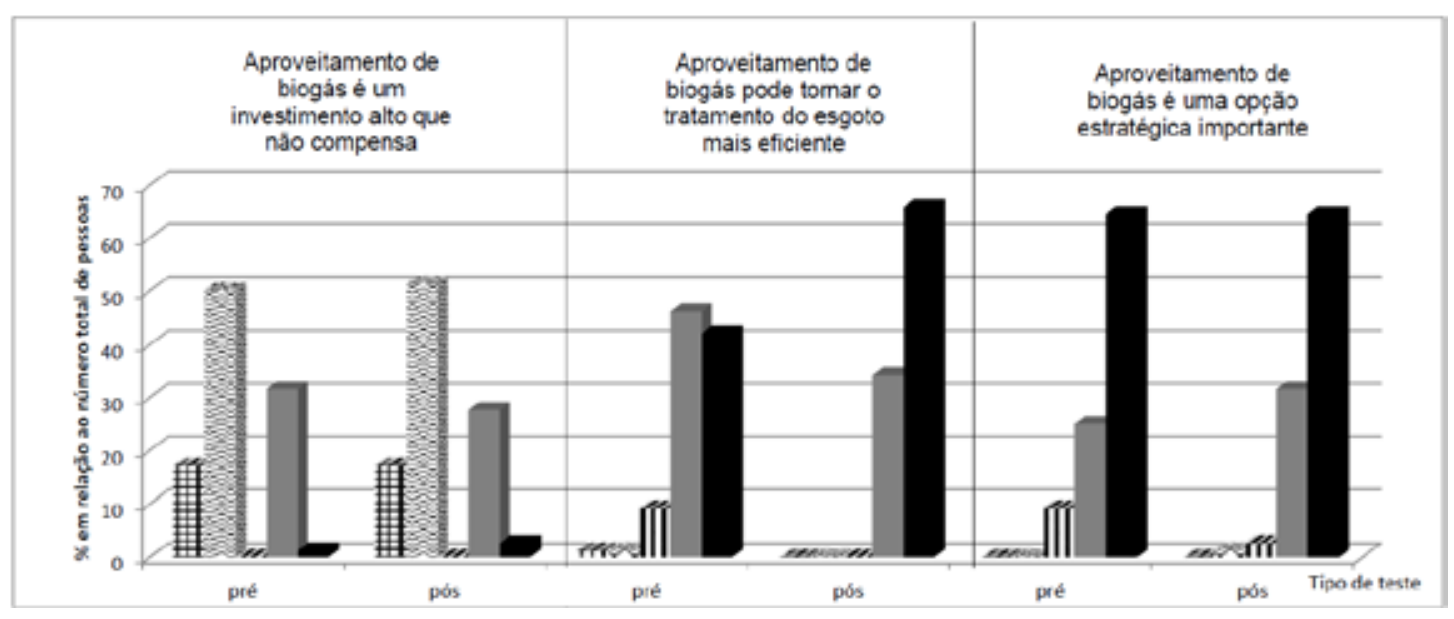

Figura IV. Percepção dos participantes do curso quanto aos critérios de gestão financeira e investimentos às ETEs em relação ao aproveitamento energético do biogás no pré e pós teste aplicado. 曲 Discordo totalmente; ※Discordo parcialmente; IIIIIIndiferente; Concordo parcialmente; Concordo plenamente. 
A Figura $V$ apresenta a percepção dos participantes quanto aos critérios de melhoria nas condições de trabalho nas ETEs, em que se nota uma média de 94\% de pessoas, tanto na pré como na pós avaliação, que concordam parcial ou plenamente que gerenciar o biogás pode minimizar maus odores nas ETEs. Esse resultado é acompanhado com a mesma tendência no que tange à minimização de passivos ambientais nas ETEs, já que $97 \%$ das pessoas também concordaram parcial ou plenamente, em ambas avaliações, que os problemas com disposição de lodo e reclamações da vizinhança quanto a maus odores ou condições sanitárias podem ser minimizados como consequência do aproveitamento de biogás. Essa possibilidade de redução de passivos ambientais motivou os trabalhadores que participaram do curso, já que $77 \%$ das pessoas em ambas as avaliações se declaram plenamente motivadas a trabalhar em ETEs com aproveitamento de biogás.

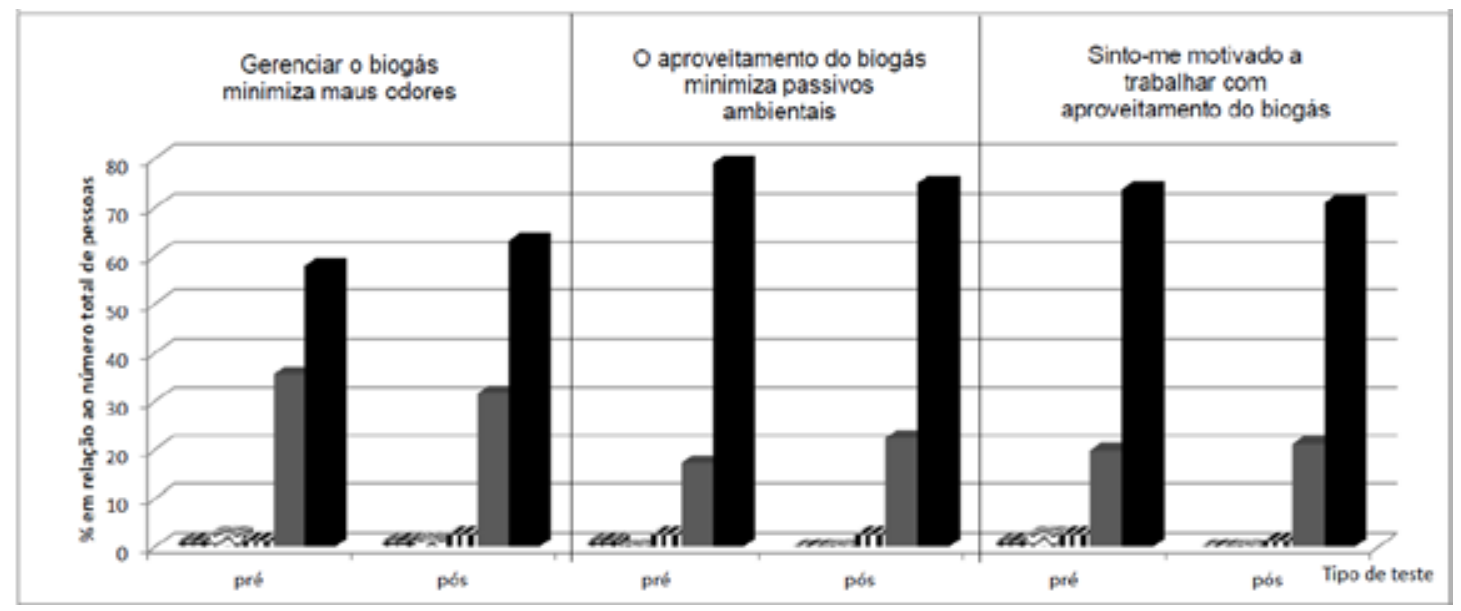

Figura V. Percepção dos participantes do curso quanto a melhorias nas condições de trabalho nas ETEs em relação ao aproveitamento energético do biogás no pré e pós teste aplicado. \#曲 Discordo totalmente; ※ $\approx$ Discordo parcialmente; IIIIIIndiferente; Concordo parcialmente; Concordo plenamente.

Por fim, a Figura VI apresenta a percepção dos participantes quanto a alterações nas rotinas operacionais nas ETEs, em que se nota que na pré-avaliação $51 \%$ das pessoas concordaram parcial e $24 \%$ plenamente que ETEs com aproveitamento de biogás possuem maior complexidade e mais atividades de rotina operacional. Já na pós-avaliação notou-se uma mudança de percepção: 47\% concordaram parcialmente e 37,5\% plenamente que as condições operacionais se tornariam mais complexas. Esse aumento percentual está relacionado ao maior conhecimento adquirido nas tecnologias de aproveitamento de biogás, onde os participantes puderam ter contato com o real estado da arte do uso de biogás no Brasil.
Quanto aos riscos operacionais, notou-se na Figura VI que as condições de segurança não eram determinantes para $33 \%$ das pessoas que discordaram totalmente, parcialmente ou se declararam indiferentes a esse aspecto. Entretanto, na pós-avaliação, o mesmo índice de pessoas que discordaram ou foram indiferentes caiu para $23,5 \%$, mostrando a importância de conhecer os perigos e riscos de incêndio e explosão inerentes às plantas de biogás, tópicos abordados pelo curso ministrado. Por fim, em ambas as avaliações, em média $97 \%$ das pessoas concordaram parcial ou plenamente que é necessária uma capacitação específica para os trabaIhadores das ETEs para atuar em plantas de biogás. Isso confirma novamente a necessidade de capacitação técnica apontada no item 3.1 deste trabalho. 


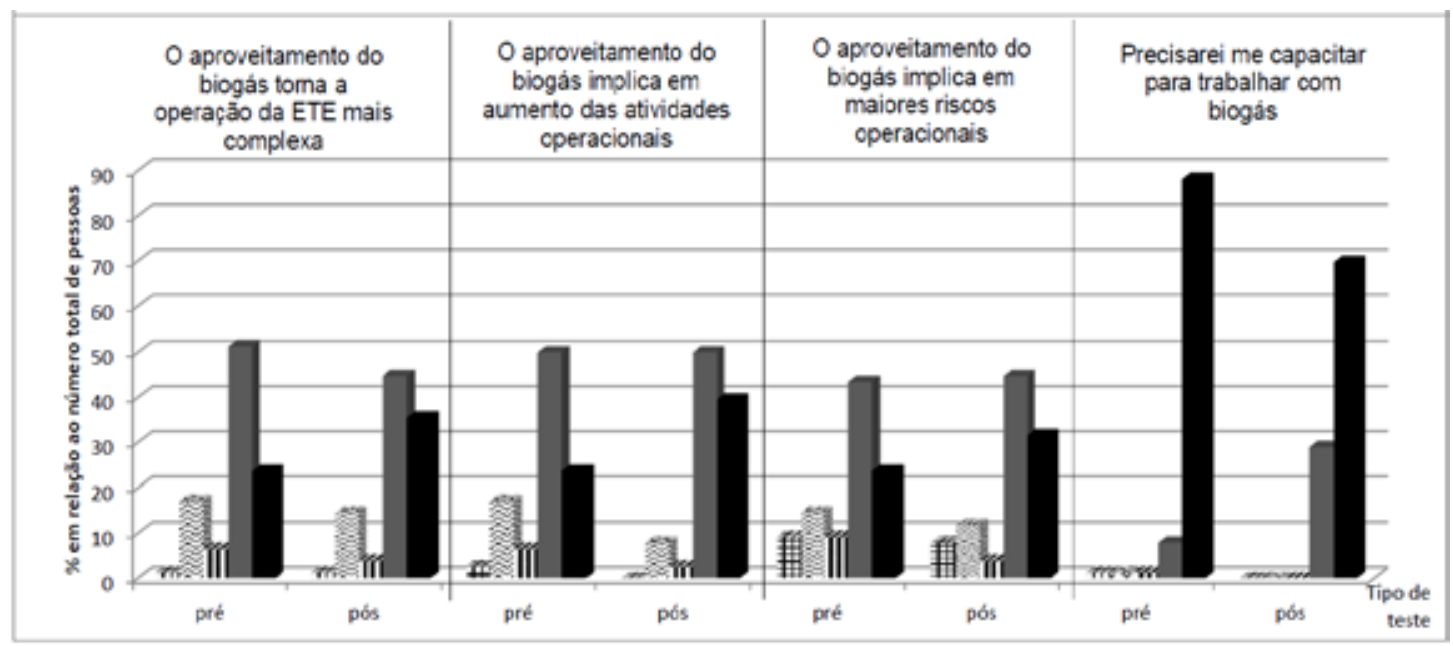

Figura VI. Percepção dos participantes do curso quanto as alterações na operação das ETEs em relação ao aproveitamento energético do biogás no pré e pós teste aplicado. \# Discordo totalmente; ※ ※ Discordo parcialmente; IIIII Indiferente; —Concordo parcialmente; $\square$ Concordo plenamente.

Nas demais avaliações, destaca-se que $85 \%$ dos participantes concordaram plenamente que adquiriram novos conhecimentos sobre a operação de uma ETE, além de $92 \%$ terem concordado que adquiriram novos conhecimentos sobre a produção de biogás e suas características. Contudo, apenas $46 \%$ concordaram que esse conteúdo está de acordo com a realidade de seu trabalho e $69 \%$ que é plenamente importante para as suas atividades. Esses últimos índices percentuais reduzidos são reflexo de ainda não existir ETEs operando com o aproveitamento energético de biogás na Sanepar. Quanto ao método utilizado no curso, $97 \%$ dos participantes ficaram totalmente satisfeitos ou satisfeitos com a estrutura, e $100 \%$ com os métodos e dinâmicas utilizados. Um aspecto bastante relevante que diferencia este curso foi a satisfação quanto à possibilidade de trazer suas experiências profissionais, apontado por $95 \%$ das pessoas. Por fim, $100 \%$ dos participantes avaliaram como alta ou muito alta a incorporação pelo instrutor das questões trazidas pelos participantes e sua capacidade explicativa e didática.

Esses resultados, principalmente quanto ao conteúdo, método e instrutor, mostram a importância e a eficiência da capacitação internacional fornecida pelo PROBIOGÁS ao instrutor, que aliou conhecimentos técnicos práticos, teóricos e novos métodos de mediação do conhecimento, principalmente pelo uso das ferramentas de ensino (cartões magnéticos para fluxogramas) desenvolvidas pela DWA.

\section{CONCLUSÕES}

O processo de capacitação sobre aproveitamento energético de biogás de ETEs desenvolvido no âmbito do PROBIOGÁS disponibilizou importantes diretrizes para a disseminação estruturada do conhecimento na área no Brasil. A estratégia de capacitação adotada facilitou a identificação de diferentes públicos que necessitam ser sensibilizados e capacitados sobre o tema.

A pesquisa de demanda por capacitação demonstrou que há interesse das prestadoras de serviços de saneamento no tema em questão e que há uma necessidade imediata de treinamento de, pelo menos, 691 profissionais do setor. Isso pode significar que as prestadoras de serviços estão avaliando novas tecnologias e procedimentos para 
melhorar sua eficiência econômica e ambiental, tendo o aproveitamento do biogás como uma forma de alcançar esse objetivo. Para tanto, a capacitação de seus operadores começa a ser vista como fator relevante. Cabe destacar que a demanda identificada pode ser considerada conservadora, uma vez que no Brasil existem atualmente menos de uma dezena de ETEs que fazem o aproveitamento energético de biogás. Logo, não existe a figura de um operador de ETEs com aproveitamento energético de biogás estabelecida. Além disso, para consolidação dessa tecnologia, não somente os operadores devem ser capacitados, mas também os gestores e projetistas, ampliando a demanda por capacitação quantificada.

A proposição de uma grade curricular para a criação de cursos formais nas instituições de ensino é um importante resultado atingido pelo grupo de multiplicadores e representa um marco para o setor de saneamento rumo à formalização e direcionamento de uma função específica na ETE. Como a grade curricular é flexível e propõe conteúdos desde o tratamento de esgoto até o aproveitamento do biogás, ela se torna referência para a criação de diferentes cursos, que podem ser adaptados às necessidades regionais das prestadoras de serviços de saneamento. Um ponto importante desse processo é a elaboração do documento por profissionais do setor de educação em parceria com profissionais do setor de saneamento, assegurando que a proposta de curso atenda às necessidades dos empregadores desses profissionais. A discussão ainda da grade curricular no âmbito do Comitê Temático em Formação Profissional em Energias Renováveis e Eficiência Energética do MEC garante a disseminação desse conteúdo às diferentes instituições que compõem a rede federal de ensino. Portanto, ao final desse processo, tem-se uma proposta de capacitação de abrangência nacional e que resguarda as especificidades regionais do país.
A capacitação dos multiplicadores, tanto de institutos de educação como das prestadoras de serviços de saneamento, também foi um passo importante para a disseminação do conhecimento, tanto na forma de cursos de pequena duração como na inserção do tema em grades curriculares existentes.

Com relação aos projetos de transferência de conhecimento, pode-se afirmar que a iniciativa desenvolvida no Estado do Paraná foi implementada com sucesso, gerando impactos positivos para o multiplicador do conhecimento, para a prestadora de serviços de saneamento e para os indivíduos capacitados. Evidenciou-se a contribuição do treinamento para um aumento do conhecimento técnico dos participantes, de suas visões sobre a relevância da inserção do biogás em sua rotina operacional e em suas motivações em trabalhar com o tema. Os resultados das avaliações demonstram que há espaço para discussões com os profissionais diretamente afetados pelas mudanças operacionais que o aproveitamento do biogás pode gerar nas ETEs. Adicionalmente, diagnosticou-se que há uma necessidade de se capacitar mais profissionais no tema.

Por fim, sabe-se que o setor de esgotamento sanitário no Brasil ainda carece de uma valorização profissional e de profissionais qualificados para operar os sistemas. Isso pode ser um entrave para o crescimento do número de plantas de biogás em ETEs no país, já que exige um monitoramento e uma operação mais complexos. O biogás, porém, pode ser um fomentador de novas práticas nas ETEs e um motivador para o profissional que queira se qualificar e melhorar o desempenho operacional dos locais onde atua.

De qualquer forma, a capacitação sobre biogás de ETEs necessita ser ampliada para todas as regiões do país, a fim de trazer novas perspectivas para a prestação de serviços de tratamento de esgoto e contribuir diretamente para que esses serviços sejam mais sustentáveis e eficientes. 


\section{AGRADECIMENTOS}

Os autores agradecem a todas as instituições que participaram do treinamento internacional de multiplicadores, bem como aqueles que contribuíram para o desenvolvimento das atividades do PROBIOGÁS.

\section{REFERÊNCIAS}

AZEVEDO NETTO, J. M. D. Aproveitamento do gás de esgotos. Revista DAE, nº 41, p. 30, 1977.

BALAT, M.; BALAT, H. Biogas as a Renewable Energy Source - A Review. Energy Sources, Part A: Recovery, Utilization, and Environmental Effects. v. 31, ${ }^{\circ}$ 14, p.1280-1293, 2009.

BOUGRIER, C.; DELGENES, J.P.; CARRERE, H. Combination of thermal treatments and anaerobic digestion to reduce sewage sludge quantity and improve biogas yield. Trans IChemE, Part B. Process Safety and Environmental Protection, 84(B4), p. 280-284, 2006.

BRASIL. Ministério da Educação. Portal MEC. Disponível em: <http://portal.mec.gov.br/index.php?option=com_docman $\&$ view $=$ down load\&alias $=41271$-cnct-3-edicao-pdf\&category_slug=maio $-2016-$ pdf\&ltemid=30192 $>$. Acesso em jan. 2016.

BRASIL. Ministério das Cidades. PROBIOGÁS. Disponível em: http://www.cidades.gov.br/saneamento-cidades/probiogas. Acesso em dez. 2016.

BRASIL. Ministério das Cidades. SNIS. Tabela resumo de informações e indicadores por abrangência. Disponível em: <http://www.snis.gov.br/diagnostico-agua-e-esgotos/diagnostico-ae-2015>. Acesso em 22 dez. 2016.

CABRAL, C. B. G. Avaliação da produção de biogás para fins energéticos em reatores anaeróbios tratando esgoto sanitário. Dissertação (Mestrado), Universidade Federal de Santa Catarina. Florianópolis, p. 139. 2016.
CAMARGO, E. B. Aproveitamento do metano do gás de esgoto em veículos. Revista DAE, n 129 , p. 5, 2009.

CHERNICHARO C. A. L.; VAN LIER, J. B. NOYOLA, A.; RIBEIRO, T. B. Anaerobic sewage treatment: state of the art, constraints and challenges. Ver. Environ. Sci. and Biotechnol., v. 5: p. 3-19, 2015.

CHERNICHARO, C. A. L.; STUETZ, R. M.; SOUZA, C. L.; MELO, G. C. B. Alternativas para o controle de emissões odorantes em reatores anaeróbios tratando esgoto doméstico. Eng. Sanit. Ambient., v. $15, n^{\circ} 3$, p. 229-236, 2010.

CHERNICHARO, C. A. D. L et al. Panorama do tratamento de esgoto sanitário nas regiões Sul, Sudeste e Centro-Oeste do Brasil: tecnologias mais empregadas. No prelo, Belo Horizonte, 2017.

COSTA, W. P. Desenvolvimento institucional e dos recursos humanos das empresas estaduais de saneamento. Revista DAE, ed. nº 104, p. 4, 1970.

ICLEl 2010. Manual para Aproveitamento de Biogás Volume 2 - Efluentes Urbanos, p. 70. São Paulo. 2010. Disponível em: < http://docplayer.com. br/3646926-Volume-2-efluentes-urbanos.html>. Acesso em dez. 2016.

IPCC - Intergovernmental Panel on Climate Change. 2006 IPCC Guidelines for National Greenhouse Gas Inventories. Japão. 2006.

McCARTY, P.L.; BAE J.; KIM, J. Domestic wastewater treatment as a net energy producer can this be achieved? Environ. Sci. \& Technol., v. 45, p. 71007106, 2011.

NOYOLA, A., MORGAN-SAGASTUME, J.M.; LÓPEZ-HERNÁNDEZ, J.E. Treatment of biogas produced in anaerobic reactors for domestic wastewater: odour control and energy/resource recovery. Reviews in Environmental Sciences and Bio/ Technology, v. 5, p. 93-114, 2006. 
NUCASE - Núcleo Sudeste de Capacitação e Extensão Tecnológica em Saneamento Ambiental. Rede de Capacitação e Extensão tecnológica em Saneamento Ambiental - ReCESA. Disponível em: $<\quad$ http://nucase.desa.ufmg.br/?page_id=256>. Acesso em dez. 2016.

PLANSAB. Plano Nacional de Saneamento Básico. Disponivel em: <http://www.cidades.gov.br/images/stories/ArquivosSNSA/Arquivos_PDF/plansab_06-12-2013.pdf>. 2013. Acesso em dez. 2016.

PORTAL SANEAMENTO BÁSICO. A importância da capacitação dos técnicos em saneamento no Brasil. 06 junho 2013. Disponivel em: <http://www.saneamentobasico.com.br/portal/ index.php/geral/a-importancia-da-capacitacao-dos-tecnicos-em-saneamento-no-brasil/>. Acesso em dez. 2016.

PÖSCHL, M.; WARD, S.; OWENDE, P. Evaluation of energy efficiency of various biogas production and utilization pathways. Applied Energy, v. 87, p. 3305-3321, 2010.

PROBIOGÁS. Resultados e Perspectivas. Seminário de Encerramento PROBIOGAS: Resultados e Perspectivas. Ministério das Cidades, Brasília. 22 fev. 2017.

ReCESA - Rede de Capacitação e Extensão Tecnológica em Saneamento Ambiental. Esgotamento sanitário: operação e manutenção de sistemas simplificados de tratamento de esgotos: guia do profissional em treinamento: nível 2 / Secretaria Nacional de Saneamento Ambiental (org.). Belo Horizonte: ReCESA, 2008. 112 p.

REPARTIÇÃO DE ÁGUAS E ESGOTOS DE SÃO PAULO. Curso para a formação e aperfeiçoamento de tratadores e auxiliares de tratamento de esgotos. Revista DAE, v. 20, p. 5, 1991.

ROSA, P. A.; LOBATO, L. C. S.; BORGES, J. M.; MELO, G. C. B.; CHERNICHARO, C. A. L. Potencial energético e alternativas para o aproveitamento do biogás e lodo de reatores UASB: estudo de caso Estação de tratamento de efluentes Laboreaux (Itabira). Eng. Sanit. Ambient., v. 21, nº 2, p.315-328, 2016.

ROSENFELDT, S. et al. Avaliação da viabilidade econômica do aproveitamento energético do biogás por meio de motor-gerador em uma ETE. In: $28^{\circ}$ Congresso Brasileiro de Engenharia Sanitária e Ambiental, Anais 2015.

SILVA, N. A. D. O biogás e o biofertilizante no balanço energético do Brasil. Revista DAE, v. 44, $n^{\circ}$ 136, p. 8, 1992.

SILVEIRA, B. et al. Guia técnico de aproveitamento energético de biogás em estações de tratamento de esgoto. Brasília, DF. Ministério das Cidades, p. 183, 2015.

VALENTE, V. B. Análise de viabilidade econômica e escala mínima de uso do biogás de reatores anaeróbios em Estações de Tratamento de Esgoto no Brasil. Dissertação (Mestrado em Planejamento Energético) - UFRJ/COPPE, Rio de Janeiro, 2015.

VAN HAANDEL. A.; KATO, M.T.; CAVALCANTI, P.F.F; FLORENCIO, L. Anaerobic reactor design concepts for the treatment of domestic wastewater. Reviews in Environmental Science and Bio/Technology, v. 5, p. 21-38, 2006.

YANWEN SHEN, J.L.; LINVILLE, M.U.; MINTZ, M.M.; SNYDER, S.W. An overview of biogas production and utilization at full-scale wastewater treatment plants (WWTPs) in the United States: Challenges and opportunities towards energy-neutral WWTPs. Renewable and Sustainable Energy Reviews v. 50, p. 346-362, 2015.

ZAWADZKI, R. A. F. O.; JAWORSKI, W. I.; FLORES, J. P. Novas rotinas operacionais como forma de melhoria de processo e redução de custos em um sistema de lodos ativados: estudo de caso. Revista AIDIS de Ingeniería y Ciencias Ambientales, v. 9, n² 2, p. 290-302, 2016. 